Relatorio

\title{
ÍNTIMO E SOCIAL
}

Gloria Picazo

Centre d'Art la Panera (Lleida) 

A miña intervención vaise centrar no traballo de cinco artistas españolas coas que colaboramos desde que a fins de 2003 se puxera en marcha o Centre d'Art la Panera en Lleida. A intensidade e dedicación coa que traballamos para levar a cabo os seus proxectos e presentalos no noso centro permitiunos reflexionar sobre distintas cuestións, non só artísticas, senón tamén sociais e políticas, presentes no desenvolvemento dos seus traballos.

E, co gallo desta intervención en Santiago de Compostela, volvemos a vista atrás para observar polo miúdo os cambios que se produciron no traballo das artistas españolas, desde as achegas daquelas artistas que na década dos setenta se vincularon co movemento conceptual. Todas elas desenvolveron unhas propostas ás que, malia que a corrente dominante nas décadas posteriores insistiu en esquecelas e ir por outros rumbos, hoxe podemos concederlles o mérito de seren pioneiras na análise do espazo que a muller debía ocupar, non só na creación contemporánea, mesmo tamén na sociedade española posfranquista.

Non podemos afirmar en ningún caso que as achegas daquel momento tivesen unha influencia notoria nas artistas españolas de xeracións posteriores, xa que o seu traballo ou ben se desenvolveu fóra do país, ou ben evolucionou cara a outras propostas artísticas, ou ben foi ignorado e houberon de pasar bastantes anos antes de que exposicións como Fuera de formato, realizada no Centro Cultural de la Villa de Madrid en 1983, Barcelona-Paris-Nueva York, no Palau Robert de Barcelona en 1985, ou Idees $i$ actituds. Entorn a l'art conceptual a Catalunya 1964-1980, no Centre d'Art Santa Mònica de Barcelona en 1992, tivesen un mínimo de incidencia en xeracións máis novas. A restante actividade expositiva desenvolveuse en espazos alternativos, como Metrònom en Barcelona ou o Espacio P en Madrid, así como esporadicamente nalgunha galería comercial, como a Galería Ciento de Barcelona ou Vijande en Madrid. Tamén cómpre destacar a importancia que na década dos setenta tiveron institucións como o Instituto Francés ou o Goethe Institute, que serviron como núcleos de infor- 


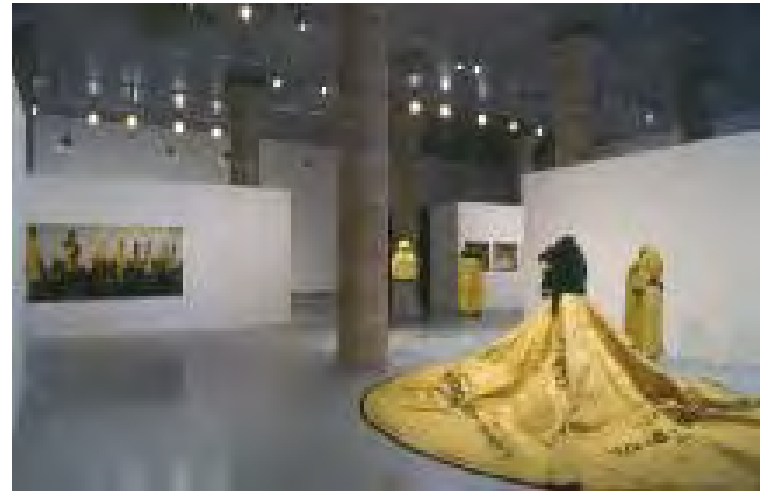

Alicia Framis: Anti-Dog, Centre d'Art la Panera, Lleida (2004)

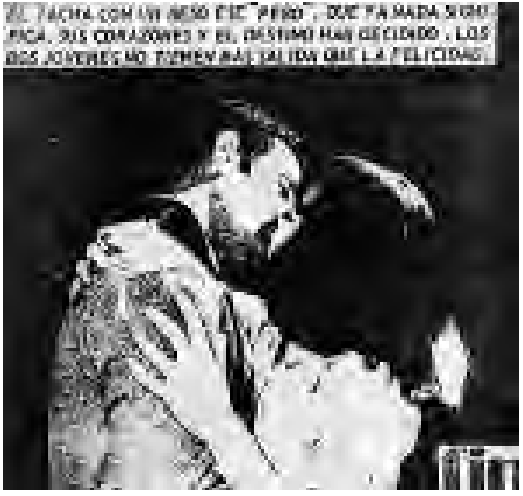

Eugènia Balcells: Fin (1978)

mación, realmente significativos para o desenvolvemento do movemento conceptual.

En definitiva, aínda hoxe está por facer unha exposición exhaustiva e relevante do que significou ese período na arte española e quizais si que, a partir desta contribución, se poderán producir influencias relevantes en xeracións posteriores. Exposicións individuais como as de Muntadas, Francesc Torres, Juan Hidalgo, Esther Ferrer ou Eugènia Balcells, tanto en Madrid como en Barcelona, e o labor realizado polo MACBA no tocante ás súas coleccións para explicar en parte este momento, foron achegas moi valiosas, pero aínda non supuxeron unha contribución definitiva. Pola contra, exposicións como El arte sucede. Origen de las prácticas conceptuales en España, 1965-1980, presentada no Museo Nacional Reina Sofía, en 2005, máis que afondar en conceptos e problemas, tanto artísticos como sociais e políticos, tenderon a unha obxectualización e descontextualización das obras, e xa que logo a unha triste banalización deste período artístico, tan significativo para a arte española do século XX.

Por todo isto, a intención desta intervención é tratar de establecer, non tanto a incidencia das propostas conceptuais, senón aqueles fíos condutores que se iniciaron nese momento e que persisten na actualidade, obviamente con diferentes formulacións, pero cun obxectivo similar, malia os anos transcorridos.

As achegas de Alicia Framis, Cabello/Carceller, Ana Laura Aláez e Marina Núñez, que hoxe analizaremos, pouco lles deben a aquelas artistas españolas dos 


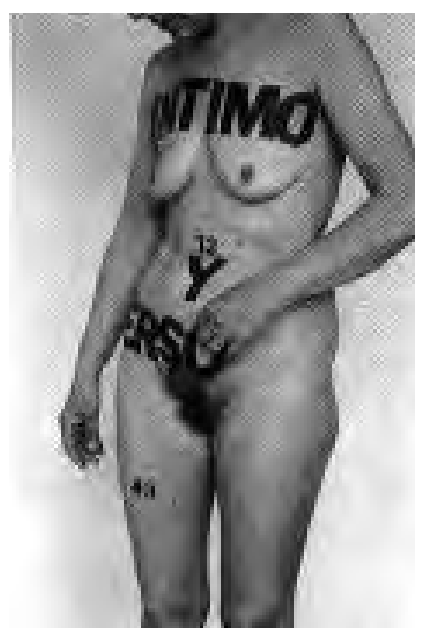

Esther Ferrer: Íntimo y personal (1987)

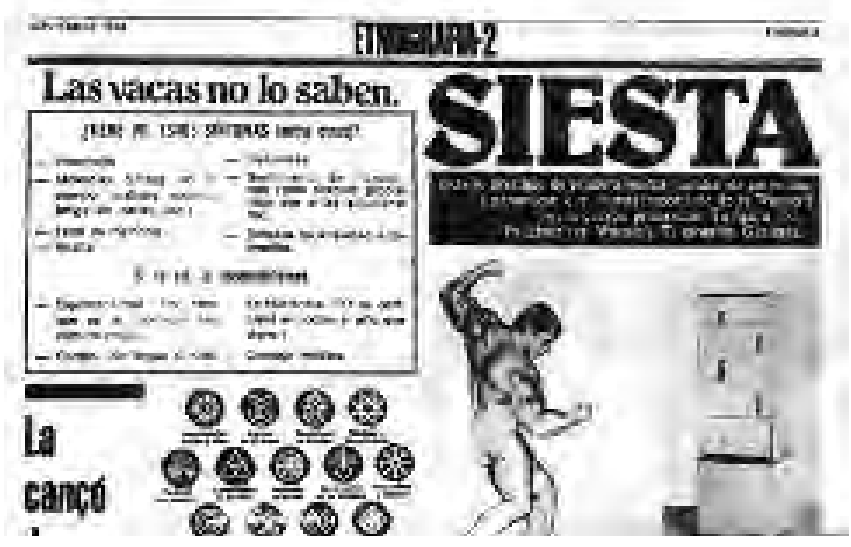

Eulàlia Grau: Etnografía (1974)

setenta, como Esther Ferrer, Fina Miralles, Eulàlia Grau ou Eugènia Balcells. Pola contra, estas artistas formáronse e observaron ao son das numerosas exposicións de arte internacional que se realizaron no noso país durante a década dos oitenta, e tiñan un afán insaciable por situarse no panorama artístico internacional, tras o longo período franquista. E, xa que logo, artistas como Louise Bourgeoise, Meret Oppenheim, Cindy Shermann ou Barbara Kruger, por só citar uns nomes, pasaron a formar parte de modelos de referencia. Pero tamén algunhas artistas españolas novas partiron a outros países para formarse ou traballar, quer porque a cidade lles ofrecía moitos estímulos, como era o caso de Nova York, quer porque as súas escolas de arte eran realmente significativas, como no caso de Amsterdam ou de Grenoble. Por exemplo, Alicia Framis nunca dubidou en afirmar a importancia crucial que as súas clases con Marina Abramović tiveron no desenvolvemento do seu traballo no eido da performance.

$\mathrm{Na}$ actualidade, o papel que en España desempeñan as institucións públicas, museos e centros de arte está a ser determinante para o traballo desta xeración máis recente, pois a anterior non tivera estas oportunidades no seu momento e as achegas de Esther Ferrer, Concha Jerez e Eugènia Balcells non se recuperaron e potenciaron senón co paso dos anos. Así mesmo, outro feito relevante foi a importancia do mercado artístico para a xeración máis nova, que sen dúbida nin- 


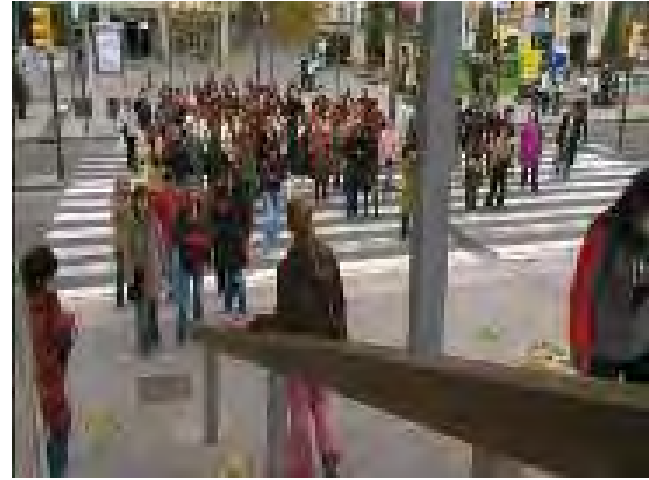

Alicia Framis: 5 pensando en ella (2005)

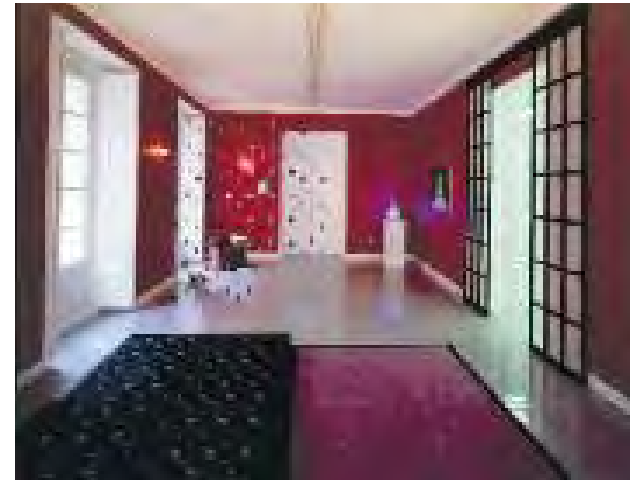

Ana Laura Aláez: Sade, Galería Juana de Aizpuru, Madrid (1999)

gunha contribuíu á difusión dos seus traballos. O circuíto comercial asumiunos con total normalidade, cousa que nin sequera pensara a xeración precedente.

Tamén existen diferenzas notorias no tocante á toma de posición dunhas e das outras. $\mathrm{Na}$ década dos setenta, estas artistas obraban en consecuencia co momento sociopolítico que vivía, non só España, senón a comunidade internacional, por mor das rupturas que suscitou o maio do sesenta e oito. Defendían a necesidade de expresarse libremente e por iso os seus traballos optaban por unha liña crítica realmente feminista, aínda que o certo é que as súas posicións non defenderan nunca abertamente cuestións de xénero. Tampouco expuxeron claramente as súas propias situacións persoais e poucas se declararon feministas, no sentido que o contexto anglosaxón e francés lle daban ao termo, moito máis elaborado intelectualmente e xa que logo asumido por pensadoras e artistas. Sen dúbida ningunha, os seus traballos eran críticos e trataban de dignificar o rol da muller na sociedade, pero as súas propostas adoitaban ser moi abertas e deixábanlle a resposta crítica ao espectador.

E realmente só moi a posteriori se empezaron a realizar lecturas do momento desde ópticas feministas, como por exemplo as levadas a cabo por Carmen Navarrete, María Ruido e Fefa Vila, xa no século XXI, co gallo do proxecto Desacuerdos, impulsado polo MACBA. No seu momento e mesmo moi posteriormente, foron poucas as revisións que, desde o punto de vista feminista, foron levadas a cabo dese período, nin polos seus observadores próximos, como Simón Marchán, Carles H. Mor ou o contorno crítico de Alexandre Cirici, nin mesmo 


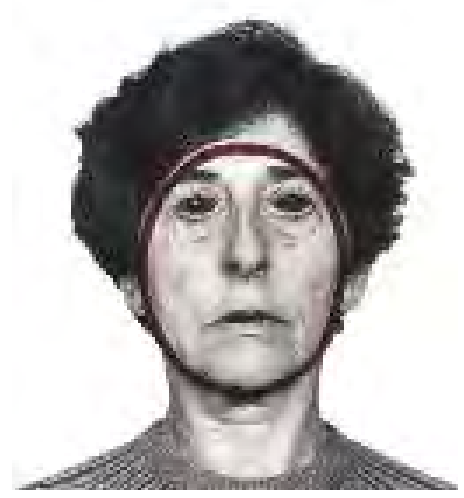

Esther Ferrer: El libro de las cabezas (1973-1981)

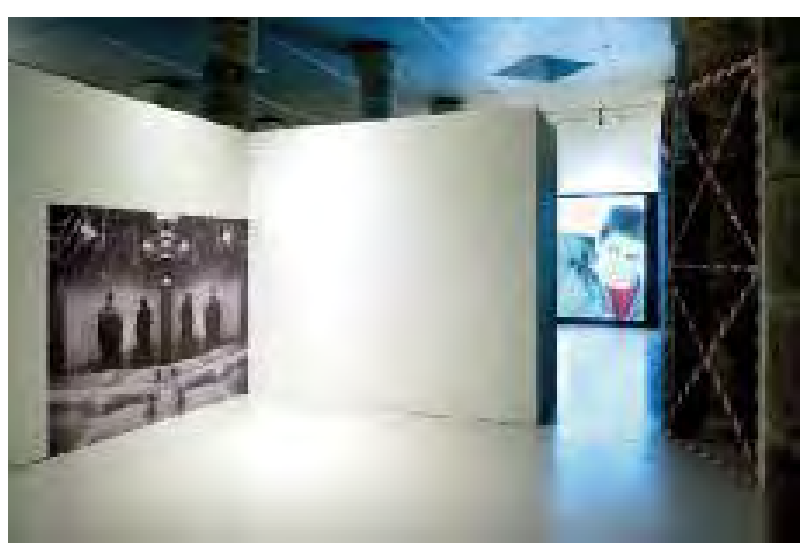

Cabello/Carceller: En construcción (capítulo 2), Centre d'Art la Panera, Lleida (2005)

na mostra máis rigorosa realizada ata o de agora, como a xa citada Idees $i$ actituds. Tan só Assumpta Bassas, nun texto do catálogo da exposición retrospectiva que o Museu d'Art de Sabadell lle dedicou a Fina Miralles, introduciu este punto de vista e relacionouno co contexto internacional ${ }^{1}$.

Afirmar a propia identidade, establecer unha nova relación consigo mesma, co propio corpo e, en consecuencia, fortalecer novas relacións co outro, pasando do persoal ao social, denunciar todo aquilo que converteu a muller en vítima e así cuestionar roles, valores e estereotipos, que acheguen novas visións verbo das cuestións de xénero na actualidade, son algúns dos aspectos que, con matices e diferenzas, podemos atopar nos traballos das devanditas artistas: Alicia Framis, Ana Laura Aláez, Cabello/Carceller e Marina Núñez, que imos comentar, pero ás que tamén poderiamos engadir os exemplos de Eulàlia Valldosera, Pilar Albarracín, o colectivo Irreakzioa/Reacción, Itziar Okariz ou Carmela García, entre outros.

No caso de Alicia Framis, presentamos no Centre d'Art la Panera, en febreiro de 2004, o proxecto Anti-dog, cunha ampla selección de vestidos, fotografías, vídeos, maquetas e obxectos. Todo xira arredor da violencia de xénero, denuncia abertamente a violencia exercida contra a muller, indaga nos mecanismos que provocan e rexen o medo e denuncia a situación da muller, facendo especial

\footnotetext{
${ }^{1}$ Véxase Assumpta Bassas, 2001, p. 92-107.
} 


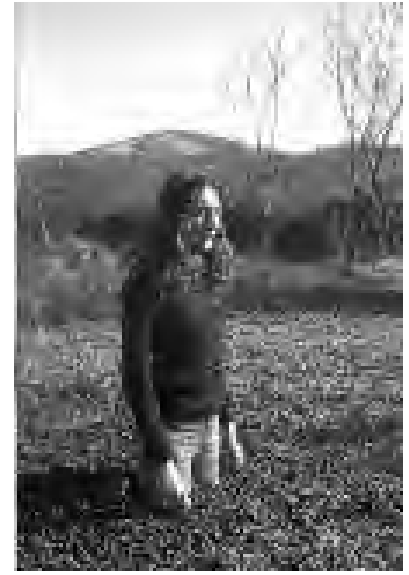

Fina Miralles: Dona-arbre (1973)

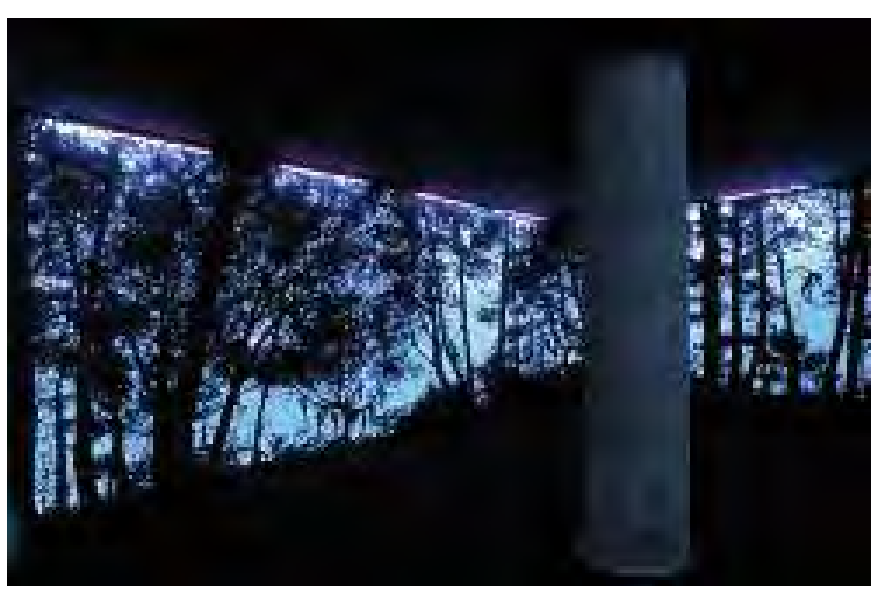

Marina Núñez: La selva (2004)

fincapé nos problemas engadidos cando se trata de mulleres inmigrantes e aparecen indicios de racismo. En Birmingham asistiu a mulleres que vivían en casas de acollida e con elas confeccionou unha lista de frases que non querían volver escoitar nunca máis. Esas frases foron incorporadas á súa colección de vestidos Anti-dog: "Este non é o teu país», "As estranxeiras estanse a levar os nosos cartos», "Volta a onde pertences» ou "Fóra da miña vida, bruxa horrible», entre outras moitas. Esas mulleres foron as que usaron eses vestidos de cinco metros de diámetro na Victoria Square de Birmingham en maio de 2003, denunciando así a violencia verbal contra as mulleres.

Como ela dicía, pertence a unha xeración que fai arte coas cousas que a rodean e sempre tratou de que, coas súas propostas, o espectador perciba unha experiencia intensa, máis que un obxecto artístico. Unha experiencia capaz de alcanzar a súa sensibilidade e de facer reflexionar sobre cuestións, tanto persoais e ás veces dificilmente confesables, como sociais. Neste sentido, un traballo como Hijas sin hijas, que tomaba como protagonistas a cen mulleres de Amsterdam e Barcelona que por motivos diferentes decidiran non ter fillos, co propósito todas elas de explorar outras posibilidades vitais. Así e todo, o traballo non se contentaba só con iso, senón que, tratando de indagar moito máis nunha cuestión tan íntima, lles preguntaba a esas mesmas cen mulleres: «que é o que deixarás cando morras?». As respostas mostran por si mesmas a intensidade do 
proxecto e poñen de manifesto de que forma tan sutil e profunda se cuestiona e facía que nos cuestionásemos algunhas das pautas de comportamento presentes na sociedade actual:

«Deixarei o meu corpo».

«Amigos que non poderei levar».

«Levarei as miñas mentiras».

«Deixarei a miña angustiosa soidade».

«A procreación non é a identidade da miña feminidade, non deixarei fillos, non, pero si unha atención continuada, que ocupa todos os meus días e as miñas noites, un murmurio».

En definitiva, tratábase de crear un lugar de encontro, pero que, asemade, fose un espazo de conflito, de dúbida e de reafirmación, e todo iso en clara referencia ao escritor Enrique Vila-Matas (AA.VV., 2003, p. 44-47).

O seu interese pola Arquitectura contemporánea e polos comportamentos privados e públicos na sociedade actual levouno a pensar en construcións arquitectónicas que servisen para repensar as relacións persoais na gran cidade e para tratar de contrariar moitas das convencións que rexen as relaciones de parella, e de aí xurdiron proxectos de habitáculos como López-Nakamura, Casas emparejadas e Apart together, nos que os tradicionais «fogares familiares» quedan aniquilados con esta posibilidade de unir e separar estancias.

Chegados a este punto en que as relacións persoais se converten en motivo central de indagación, vexamos como tres décadas atrás Eugènia Balcells trataba de desenmascarar os mecanismos de expresión utilizados pola ideoloxía dominante a mediados da década dos setenta, no tocante aos roles femininos e masculinos, nun momento en que no noso país empezaba a cambalear o réxime franquista e principiaba unha aínda dubitativa etapa predemocrática. Fin (1978) adoptou o formato de instalación e de libro e mostraba unha recompilación de imaxes de parellas a partir dos estereotipos que ofrecían as fotonovelas, que tanta aceptación tiñan nese momento entre o público feminino. Sobre esta obra, Eugeni Bonet escribiu en 1979: «Fin é aquí a expresión sintetizada de toda a carga alienante e reaccionaria da fotonovela do corazón, medio ampla- 
mente dirixido ás capas medias e baixas da sociedade, e especialmente ás mulleres -as súas principais lectoras-, e o exemplo dunha visión de parella e, por extensión, da institución familiar -ademais doutras moitas connotacións. Neste caso, a forza crítica e a contundencia do traballo veñen determinadas pola monotonía das propias imaxes, que quedan reducidas a pura condición de cliché» (Bonet, 1979, p. 7).

Dado que un dos seus máximos intereses era, nese momento, a importancia dos medios de comunicación e o seu papel na propagación de discursos dominantes, para realizar o proxecto Boy meets Girl, a artista reuniu imaxes de parellas sacadas da prensa diaria, de revistas e de anuncios publicitarios. Illou, clasificou e descontextualizou numerosas imaxes de parellas, co propósito de ironizar sobre estas relacións, deixando que fose a evidencia das propias imaxes, pero sobre todo as miradas críticas dos que observaban o seu traballo, as que tiraran as súas conclusións.

$\mathrm{Na}$ instalación Re-prise (1976-1977) utilizou oito programas con oitenta diapositivas. Cada diapositiva correspondía a un fotograma real de películas comerciais que circularan polas canles de exhibición habituais e as seiscentas corenta diapositivas estaban ordenadas en oito eixes temáticos: Xenéricos; Personaxes femininos; Personaxes masculinos; Acción: acenos, mans; Relación: a parella; Situación: o teléfono; As masas; e The End. Con todo isto, Eugènia Balcells ordenou unha serie de tipoloxías dalgúns dos arquetipos más habituais do cine comercial, para sinalar eses códigos tan sumamente coñecidos no desenvolvemento das historias cinematográficas.

En Going through languages (1981) recorreu novamente aos estereotipos femininos no cine e os medios de comunicación, a partir de filmacións do concurso de Miss Universo 1981. Como di Eugènia Balcells, é «unha contraposición entre a imaxe da muller vehiculizada polos medios de comunicación e o corpo da muller que eu denomino "estando/sendo", é dicir, o corpo da muller sen finalidade ningunha. Un corpo habitado ou un corpo utilizado» ${ }^{2}$. É un proxecto moi na liña do realizado, por exemplo, por Annette Messager con As torturas voluntarias, para o que tamén utilizou fotografías de revistas que mostraban mulleres sometidas a todo tipo de «torturas» cosméticas.

\footnotetext{
${ }^{2}$ Véxase Álvarez Basso, 1995, p. 86-87.
} 
Estamos a ver como ese «eu» feminino, íntimo e persoal -utilizando neste caso o título dunha obra de Esther Ferrer- vai franqueando o persoal para internarse no social, cuestionando roles e valores ao uso, rompendo tabús, enfrontándose a estereotipos, denunciando inxustizas e violencias, e de todo isto xurdiron, nun momento dado, traballos como os de Eulàlia Grau e Esther Ferrer, e na actualidade propostas como as de Cabello/Carceller, Ana Laura Aláez e a devandita Alicia Framis.

Houbo un momento en que Eulàlia Grau falou do papel social da muller nun traballo realmente significativo, como foi Discriminación de la mujer, e atreveuse a introducir, daquela, temas tan insólitos como o papel da Xustiza e a situación da muller nas prisións do noso país, mostrándoa dobremente discriminada e explotada. Cunha linguaxe realmente pobre -o collage foi o seu principal medio de expresión-, pero conciso pola rotundidade das imaxes seleccionadas, denunciou a subordinación da muller, contrapoñendo os roles masculinos e femininos, e novamente, como tamén fixera Eugènia Balcells, deixando que a locuacidade das imaxes e mais dos textos publicitarios seleccionados falasen por eles mesmos.

E, malia a distancia, no tocante á resolución técnica, as intencións afíns entre ambas as dúas son obvias, no momento en que Alicia Framis aceptou o reto de realizar unha acción o día 25 de novembro de 2005 en Lleida, como protesta pola morte violenta dunha cidadá local a mans da súa parella. 5 pensando en ella foi unha máis da serie de folgas organizadas pola artista; neste caso, contou coa participación de cen mulleres da cidade, que aceptaron colaborar con ela para denunciar a violencia continuada que se exerce contra tantas e tantas mulleres.

Como apunta Alicia Framis, nas performances «sempre debemos actuar. Estes vídeos rexistran o inverso, neles a performance consiste en non facer nada, en pararse, en resistir [...]. Vendo a xente detida é cando empezas a sentir angustia, angustia de comprender, de pensar no que pode pasar. Como di moita xente, é como dous segundos antes dunha catástrofe: agardas o peor» ${ }^{3}$.

O feito de cuestionar roles e valores pódese realizar cunha actitude crítica e de denuncia, pero tamén utilizando a linguaxe e as estratexias que a sociedade usa para perpetualos. Neste sentido, é evidente a intencionalidade de Ana Laura

\footnotetext{
${ }^{3}$ Véxase Piedad Solans, 2008, p. 64.
} 
Aláez, cuxas propostas recorren á provocación, ao cultivo ácido da ironía, da sedución, do desexo, do erotismo e, mesmo ás veces, retoma os códigos estereotipados usados pola pornografía. E todo isto para cuestionar a imaxe tradicional da identidade feminina, para facer fincapé na beleza artificial e efémera que se prodiga nos medios de comunicación, para exaltar o narcisismo cun cariz totalmente provocativo e, en definitiva, como dixo Octavio Zaya dela, para indagar a fondo na "psicofantasía do desexo». A selección de fotografías que mostramos na exposición El sueño erótico, realizada no Centre d'Art la Panera a fins de 2004, tena a ela mesma como protagonista, así como tantas das súas obras que mostran a súa fascinación polas diferentes identidades que habitan en cada un de nós e, xa que logo, o seu traballo vai encamiñado a mostrar as estratexias que acotío utilizamos para resaltar esas múltiples identidades, ou ben, como acontece en tantos de nós, para tratar de minimizalas, cando non de eliminalas completamente. Outro proxecto de Ana Laura Aláez destacable neste contexto é o "prostíbulo» que realizou no marco da exposición Sade, na Galería Juana de Aizpuru de Madrid en 1999. Trátase dunha habitación decorada cunha estética oriental e que ela define como unha instalación en que expón a súa intimidade e vende os seus soños: «un espazo metafórico para o relax. Un contexto confortable para o sexo e o sono reparador». Unindo sentido do humor e mais ironía, rexeitando o medo e valéndose abertamente de estratexias publicitarias para admitir que lle «gusta posar diante da cámara, pola súa capacidade de ordenar o caos, de enfocar unha realidade inventada e baixo control. Tras esta especie de rito de destrución e reinvención solapada, a túa persoa voa, figuradamente, polos aires». En definitiva, é totalmente consciente das posibles críticas ao seu traballo pola carga egocéntrica que se lle pode achacar e pola posible ambigüidade do seu discurso, pero, quizais sexa precisamente o feito de moverse neste espazo tan ambivalente o que fai atractivo o seu traballo.

Unha nudez totalmente oposta nas formas, pero quizais igual de provocadora nos resultados, é a que practicou desde os seus inicios Esther Ferrer, aínda que sen dúbida partindo de puntos de vista moi distintos. Ela mesma asegura que empezou cos autorretratos porque, nun principio, quería traballar sobre o corpo mediante a fotografía, con todas as partes do corpo: «Comecei a dicirlles aos amigos se me prestarían os seus corpos. Quería traballar co corpo, non necesariamente co meu corpo. Non quería que tivese demasiado que ver comigo. 
Pero todo se volveu difícil, porque eu quería cortar, pegar, manipular fotos de caras e partes do corpo, e a xente á que lle pedín ser modelo foi reticente, ás veces ata tiveron reaccións supersticiosas [...]. Por iso decidín que tiña que facer este proxecto co meu propio corpo, a miña propia cabeza, o meu propio sexo, etc. Era consciente de que iso cambiaría a miña maneira de traballar e, sobre todo, de que ía cambiar a interpretación que o espectador podía darlle ao meu traballo» ${ }^{4}$. E deste razoamento xurdiron proxectos como El libro del Sexo, El libro de las cabezas e Autorretrato en el tiempo, serie fotográfica, esta última, dunha dilatada extensión no tempo e que mostra sen paliativos o paso dos anos no rostro endurecido da artista. Así e todo, a súa aposta diante do público está sempre moi clara e definida, e malia que poida traballar co seu propio corpo, non defende un traballo interiorizado senón todo o contrario, posto que para ela o acto de mirar é o que lle interesa fundamentalmente ao realizar as súas performances: «a arte de mirar e ver, os outros mirándome a min e eu mirando os outros» e engadía: «Realizar performances fíxome ver os demais de forma diferente. Miro a alguén, a persoa mírame, e de súpeto xorden moitas cuestións, moitos interrogantes, empezando polo máis simple, pero o máis fundamental, no ámbito da performance. Quen é o que mira a quen? Só hai un que mira? [...]. Esta tensión de miradas, a complicidade do que mira, é interesante, especialmente cando se prolonga no tempo ${ }^{5}$. E, de aí, o paso seguinte foi que as súas accións puidesen ser realizadas por ela mesma ou ben contando coa colaboración doutras persoas, como no caso de Íntimo y personal, onde as medicións corporais pode facelas sobre o seu propio corpo, sobre o doutra persoa ou ben propón que se fagan en grupo. Isto é o que acontece tamén con Por el camino de ida y vuelta, acción en que unha persoa atravesa un espazo de dereita a esquerda, vestida, logo volve atravesalo en sentido contrario, espida. Pero tamén propón esta performance para que sexa todo un grupo o que realice a acción e que os participantes vaian quitando as prendas unha a unha.

A provocación que se mantén no seu traballo, sen dúbida reminiscencia da súa actividade inicial co grupo ZAJ, pode apreciarse, de xeito moi evidente e cunha carga de crítica corrosiva aos sistemas de poder falocéntricos, nos seus

\footnotetext{
${ }^{4}$ Véxase Marianne Bech, 2001-2002, p. 35.

${ }^{5}$ Véxase Marianne Bech, 2001-2002, p. 33.
} 
obxectos, "xoguetes educativos». Con eles critica duramente os conflitos bélicos e un feito terrible como o é o uso da violación como arma de guerra. Pero tamén noutros obxectos manipulados como en Desviación de la pornografía al servicio del arte (1985), Esther Ferrer fai referencia ao absurdo da nosa sociedade e trata de engadirlles máis elementos absurdos ao que xa por si só é absurdo, aínda que coa clara intención de denunciar a falocéntrica necesidade de control.

Movéndose nun ámbito que, como elas definiron, trata de desarticular os discursos que sosteñen a hexemonía da heteronorma no campo das representacións identitarias, Cabello/Carceller no seu proxecto En construcción (capitulo 2), mostrado no Centre d'Art la Panera a fins de 2004, presentaron o vídeo Instrucciones de uso. Manual ilustrado para un uso de la masculinidad, no que facían fincapé no «recoñecemento da masculinidade como unha construción cultural, como un modelo de comportamento que se pode adaptar a calquera corpo humano, independentemente do seu sexo biolóxico», e para iso desenvolveron un manual de xestos masculinos, sobre a acción de sentarse, ler, esperar ou vestirse, con cuxa aplicación podía conseguirse unha correcta imaxe masculina. E con Casting: James Dean (Rebelde sin causa) dezaseis mulleres interpretaban unha escena desta película tratando de parecerse o máis posible ao seu protagonista. E neste proxecto aparecen dous aspectos básicos no seu traballo, o cine, como transmisor de modelos de comportamento de fondo calado na sociedade -como tamén o fixera no seu momento Eugènia Balcells-, e o constante intercambio de xéneros entre os seus protagonistas, para centrarse nalgúns dos estereotipos que operan na construción dunha masculinidade dominante, así como investigar esas estruturas de poder que dividen os xéneros e que, xa que logo, actúan como opresores na sociedade, avogando así por identidades alternativas ás hexemónicas. Como pode apreciarse nas imaxes, o seu proxecto, instalado no espazo do Centre d'Art la Panera, convertía a súa arquitectura en pequenas salas de exhibición cinematográfica nas que as imaxes estaban presentes, pero tamén aparecían as butacas baleiras, xusto despois da proxección dunha película, uns intervalos temporais para elas cheos de contido, ao situarse antes e despois daquilo que nos «educa», ou quizais poderiamos dicir "maleduca», a través do cine.

O traballo de Cabello/Carceller tivo unha incidencia especial na cidade de Lleida e, como nunha exposición presentada anteriormente na que se trataba 
de seguir insistindo nun «non á guerra», a súa posición fronte á arte e á sociedade serviu para reivindicar diante dos grupos que nos visitaban, especialmente os adolescentes, un respecto absoluto pola liberdade sexual e diante da diferenza de xéneros.

Para finalizar falarei dun último traballo, o de Fina Miralles, unha artista que, a principios da década dos setenta, realizou unha serie de propostas en que establecía estreitos vínculos entre o corpo feminino e mais a natureza, fusionándose con ela, adoptando unha posición crítica fronte á súa destrución, no que sería un incipiente punto de partida ecoloxista. Fronte á grandilocuencia das magnas propostas de land art, impulsadas por artistas norteamericanas como Gina Pane ou Ana Mendieta e tamén por Fina Miralles neses anos, empregaron a intimidade do propio corpo, fundíndose coa natureza, para revisar a propia identidade. Na serie Relaciones (1975), conectaba o seu corpo con elementos naturais, cubríndoo con pedras, terra, area ou palla, relacionando o corpo coa auga da chuvia, do mar, coa herba, ou cos catro elementos dunha vez. No proxecto $E l$ árbol, dese mesmo ano, concedíalle a unha árbore personalidade humana, vestíndoa, falando con ela, paseándoa, colocándolle «froitos de pedra» ou «ramas de lodo». Tamén era sumamente interesante como ela se relacionaba coa árbore noutra serie titulada El árbol y el hombre, na que aparecía subida a unha árbore, atada a ela, colgada dela ou dirixíndolle unhas palabras. Vendo o título que lle deu a este traballo, podemos intuír como neses momentos as cuestións de xénero aparecían esporadicamente e as reivindicacións feministas existían, pero non tanto como unha cuestión ideolóxica plenamente asumida e, xa que logo, digna de defender, como xa se manifestaba nos contextos norteamericano e mais europeo, senón como un logro social que conseguir, dado sen dúbida o especial momento que se vivía en España, nos anos finais do franquismo, con tantos retos sociais por diante que o país pretendía superar.

E o seu traballo móvenos a reflexionar sobre o papel que a natureza xogou nestes últimos anos na obra de artistas, como veremos a continuación de Marina Núñez, que nos falará sobre a importancia da natureza no seu traballo. Unha natureza que, se no caso de Fina Miralles era reivindicada nos seus aspectos máis físicos e naturais, no de Marina Núñez se converte nun marco idóneo no que se xeran visións oníricas, ás veces apocalípticas, nas que tanto se denuncia o medo feminino, como apreciamos o horror tras unha catástrofe natural. 
Por último e volvendo aos comentarios iniciais, non se tratou tanto de establecer influencias entre xeracións de artistas, como de descubrir intereses comúns, puntos de partida similares e de observar como, ao longo de máis de tres décadas, o papel xogado por aquelas artistas puidera ter sido moito máis decisivo en xeracións máis novas, se o seu traballo puidese desenvolverse con normalidade e non tendo que seguir as súas traxectorias noutros países, ou ben tendo que abandonar irremediablemente o seu traballo. 
ÍNTIMO E SOCIAL

\section{BIBLIOGRAFÍA}

AA.VV.: Alicia Framis. Works 1995-2003, Artimo, Amsterdam, 2003.

Álvarez BASSO, C.: «Una conversación con Eugènia Balcells», en Eugènia Balcells. Sincronías, Museo Nacional Centro de Arte Reina Sofía, Madrid, 1995, p. 86-87.

BASSAS, A.: «Fina Miralles: natura, cultura i cos femení, una perspectiva des del gènere», en Fina Miralles. De les idees a la vida, Museu d'Art de Sabadell, 2001, p. 92-107.

BECH, M.: «It's all about looking. Interview with Esther Ferrer», en Esther Ferrer, Museet for Samtidskunst, Roskilde/Denmark, 2001-2002, p. 33-35.

BONET, E.: «Escoli», en Eugènia Balcells, Universitat Autònoma de Barcelona, Departament d'Art, Bellaterra, 1979, p. 7.

SOLANS, P.: «La acción como reacción», Lápiz, Madrid, n. ${ }^{\circ}$ 244, 2008, p. 49-67. 